Mirai. Estudios Japoneses

ISSN-e: 2531-145X

http://dx.doi.org/10.5209/mira.67206

\title{
Muñecas made in Japan. De las karakuri-ningyō a Danny Choo
}

\section{María Gutiérrez Montañés ${ }^{1}$}

Resumen. Entre los muchos elementos que caracterizan al País del Sol Naciente, no podemos dejar de mencionar la industria muñequera. Fue en el período Edo (1603/1615-1868) cuando esta alcanzó su mayor auge, cuando se desarrollaron las tipologías de muñecas tradicionales o ningyō que conocemos a día de hoy. La mayoría de estas piezas cumplen una función propiciatoria de buen augurio, siendo utilizadas como amuletos protectores contra los malos espíritus, así como juguetes, souvenirs o modelos de conducta. Cabe destacar que este tipo de producción se mantuvo durante las eras Meiji (1868-1912) y Taishō (1912-1926) llegando hasta la actualidad.

Evidentemente, con el paso del tiempo, los materiales y métodos de fabricación han cambiado de tal modo que podemos señalar el uso de vinilo, resina y otros plásticos, además del empleo de moldes o incluso impresoras 3D. Si bien, estas nuevas muñecas no dejan de ser interpretaciones de modelos tradicionales, adaptadas al momento de Neojaponismo actual, que vuelve la vista a manifestaciones como el manga y el anime para inspirar su forma estética. A esto, además, podemos sumarle la incorporación de elementos tecnológicos, dando como resultado ejemplos como las Smart Doll de Danny Choo entre otras muchas firmas.

Mediante este artículo queremos señalar los puntos de unión entre la tradición y modernidad, basándonos en un ejemplo concreto como son las Smart Doll, una tipología que pone de relieve la incorporación de innovación y tecnología sin perder de vista el pasado.

Palabras clave: Muñeca; ningyō; Japón; Smart Doll; Danny Choo.

\section{[en] Dolls made in Japan: From karakuri-ningyō to Danny Choo}

\begin{abstract}
Among the many elements that characterize Japan, we cannot fail to mention the doll industry. It was in the Edo period (1603 / 1615-1868) when it reached its peak, this is when the typologies of traditional dolls or ningyō we know today were developed. Most of these pieces fulfill a propitiatory function of good omen, being used as protective amulets against evil spirits, as well as toys, souvenirs or role models. It should be noted that this type of production was maintained during the Meiji (1868-1912) and Taishō (1912-1926) periods until today.

Obviously, as time went on, the materials and manufacturing methods have changed in such a way that we can point out the use of vinyl, resin and other plastics, in addition to the use of molds or even 3D printers. Although, these new dolls are still interpretations of traditional models, adapted to the moment of current Neojaponism, which returns the view to manifestations such as manga and anime to inspire their aesthetic form. In addition, we should mention the incorporation of technological elements, resulting in examples such as the Smart Doll of Danny Choo among many others.

Through this article we want to point out the points of union between tradition and modernity, based on a concrete example such as Smart Doll, a typology that highlights the incorporation of innovation and technology without losing sight of the past.
\end{abstract}

Keywords: Doll; ningyō; Japan; Smart Doll; Danny Choo.

Sumario. 1. Introducción: Muñecas tradicionales y su producción; 2. Innovación desde la tradición; 3. Tecnología y actualidad; 4. Conclusiones; 5. Bibliografía.

Cómo citar: Gutiérrez Montañés, M. Muñecas made in Japan. De las karakuri-ningyō a Danny Choo, en Mirai. Estudios Japoneses, 4, 2020, 99-105.

\section{Introducción: Muñecas tradicionales y su producción}

El término que se utiliza en Japón para identificar a las muñecas tradicionales es ningyō (人形), formado por los kanji, nin (人, persona, humano) y gyō (形, forma), de modo que su traducción literal vendría a ser "forma humana", "forma de persona" ". Este término fue traducido al inglés como doll, lo que ha llevado a que en Occidente estas piezas se identificaran con nuestra definición de muñeca como juguete infantil. Sin embargo, estos objetos no sólo cumplen esta función, sino que también pueden ser amuletos protectores contra los malos espíritus, objetos propiciatorios de

\footnotetext{
Universidad de Zaragoza; mariagutierrezmontanes@gmail.com

Yamada, T. (1955): 1
} 
buen augurio, modelos de conducta con su pertinente función didáctica, objetos de exhibición y apreciación estética o incluso souvenirs ${ }^{3}$. Si algo caracteriza a estas muñecas es el hecho de que su fabricación se lleva a cabo de manera completamente artesanal, sirviéndose de materiales como la madera, la cerámica o el papel maché.

El mayor desarrollo de su producción tuvo lugar en el periodo Edo (1603/1615-1868), una época en la que Japón vivió bajo el gobierno de los sogunes de la familia Tokugawa, que lograron unificar el país bajo su autoridad ${ }^{4}$. Esta fue una época de paz y prosperidad, lo que afecto a la producción de ningyō: en las distintas regiones del archipiélago hubo un auge de talleres artesanales y grandes nombres propios dentro de la creación de estas figuras, además, su consumo se vio propiciado por el contexto mencionado. En consecuencia, y atendiendo a tales circunstancias, la calidad y el virtuosismo de su ejecución avanzó bastante ${ }^{5}$.

Esta producción se mantuvo en las eras Meiji (1868-1912) y Taishō (1912-1926). En estas etapas, el descubrimiento y la fascinación que produjo Japón en los países occidentales, y que dio lugar al Japonismo (segunda mitad del siglo XIX y primeras décadas del XX), llevó consigo la pronta importación de este tipo de artesanías que, además, fueron dadas a conocer gracias a las exposiciones universales e internacionales. Su éxito fue tal, que pronto estas muñecas fueron vendidas en tiendas especializadas, donde fueron adquiridas por coleccionistas ${ }^{6}$.

Si bien, no podemos dejar de señalar que esta producción se mantiene en la actualidad, por supuesto, con toda una serie de variantes a tener en cuenta. En primer lugar, decir que estamos viviendo un momento de Neojaponismo: el archipiélago japonés es algo ya descubierto y conocido, pero sigue presente ese espíritu de exotismo y, en este caso, modernidad, que nos lleva a tomarlo como un modelo de referencia y atención en algunos campos, sobre todo, aquellos vinculados con la tecnología. Igualmente, y en segundo lugar, debemos señalar el hecho de que los sistemas de producción de muñecas (cuya definición en este caso estaría más cercana a ese concepto de doll que hemos comentado, si lo comparamos con las ningyō tradicionales) ha cambiado, aprovechando variantes en el diseño, así como en el sistema de producción, aunque sigue presente ese aspecto artesanal con un carácter mucho más comedido. Teniendo en cuenta lo anteriormente expuesto, encontramos una inspiración más que evidente en tipologías tradicionales de las que hablaremos en el apartado siguiente, así como ciertos préstamos estéticos o características que se comparten obedeciendo, eso sí, a las preferencias estéticas del momento que nos ocupa, y que, por supuesto, distan en algunos casos de la traición.

Mediante el siguiente texto lo que pretendemos es poner de relieve, por un lado, los nexos entre tradición y modernidad a través de las muñecas, centrándonos en un ejemplo concreto, como son las Smart Doll de Danny Choo que, además, innovan en diversos aspectos como la estructura de las figuras o incluso la implementación de accesorios y elementos tecnológicos para, a modo de conclusión y cierre, dar algunas pinceladas acerca de los avances y novedades que la creatividad ha traído consigo.

\section{Innovación desde la tradición.}

No podemos hablar de creaciones contemporáneas sin mencionar algunas tipologías de muñecas tradicionales con las que podemos establecer una cierta conexión, resaltando aspectos como su funcionalidad o bien por ser los primeros ejemplos de innovación tecnológica vinculada a este formato.

Por ello, vamos a empezar hablando de las llamadas ishō-ningyō, también conocidas como muñecas de vestir, ya que destacan por sus elaborados atuendos de excelente calidad. Respecto a sus orígenes, arrancan a principios del período Edo, siendo un reflejo de algunos tipos populares de la sociedad del momento, representando una variada galería de personajes, ya sea reales (guerreros, actores de teatro kabuki, comerciantes, etc.) o mitológicos ${ }^{7}$. En estas figuras se aprecia un especial cuidado en la disposición del atuendo, realizado normalmente con crepé, que imita las curvas y volúmenes de la tela de una forma lo más realista posible ${ }^{8}$. En cuanto a su estructura, cuentan con cabeza y extremidades de madera, que posteriormente se cubren con gofun $;{ }^{9}$ y un cuerpo, que queda oculto bajo sus atuendos, de madera o paja, mucho más simplificado en su construcción ${ }^{10}$. En cuanto a su función, estas muñecas no tienen otra utilidad que el disfrute de los sentidos de aquél que las contempla, son meros objetos de colección para ser expuestos y apreciados por su estética ${ }^{11}$.

Hemos querido comentar esta tipología por su relación con las llamadas fashion dolls que veremos después, cuyo punto en común radica en la relevancia del atuendo y su tratamiento. En el caso de las ishō-ningyō hemos dicho que su cuerpo queda completamente oculto por los tejidos. El tratamiento más simple se debe a dos motivos fundamentales, partiendo del hecho de que quedan ocultos a la vista para, y que, además, pretenden favorecer la

Gómez Pradas, M. (2011): 108.

Whitney, J. (ed.) (1991): 1-6.

Yamada, T. (1955): 12.

Pate, A. S. (2005a).

Pate, A. S. (2005b): 176.

Gribbin, J. / Gribbin, D. (1984): 80.

Se trata de una pasta compuesta por conchas marinas trituradas y un aglutinante de origen animal, extraído de piel, huesos, tendones, intestinos de mamíferos o peces, denominado nikawa, lo que aporta un acabado blanco, liso y pulido. Pate, A. S. (2005b): 15.

10 Yamada, T. (1955): 47

11 Gribbin, J. / Gribbin, D. (1984): 80. 
forma del tejido para conseguir un aspecto lo más realista posible del personaje representado. Es decir, la trama y volumen de la tela obedece a una escala humana ya que no existe un tejido específico destinado a la creación de estas figuras, para que en una muñeca se consiga un aspecto realista, normalmente se estiliza la forma del cuerpo para disponer los atuendos y accesorios sobre ella, así aquello que se ve de un golpe de vista nos da una sensación de realismo, no una desproporción. A la par que avanzamos en el tiempo, veremos que, por ejemplo, el cuerpo queda reducido a un mero cilindro sobre el que se dispone el tejido, dejando a la vista únicamente las extremidades.

Por otro lado y en este caso, relacionada con la innovación y dinamismo, debemos mencionar a las karakuriningyō, una tipología cuyo origen se encuentra estrechamente vinculado al entretenimiento popular. Consiste en una especie de autómatas que, en su interior, cuentan con una serie de mecanismos que les permiten moverse ${ }^{12}$. Sus orígenes están estrechamente relacionados con mecanismos para la navegación creados en China, como son los relojes de agua llegados desde Babilonia a Japón en torno al año $671^{13}$. Los ejemplos más primitivos se remontan al período Kamakura (1192-1333), momento en el que estas muñecas eran regaladas al emperador los monjes de Nara, aunque su momento de mayor auge lo encontramos en el período Edo gracias a Takeda Ō mi (?-1704), que mostraba sus muñecas movidas mediante el peso del agua y la arena en un pequeño teatro ${ }^{14}$. En estos casos se emplean materiales similares, pero lo que llama especialmente la atención son los complejos mecanismos de madera que se encuentran en su interior; gracias a toda una serie de ruedas y palancas la muñeca realiza un determinado gesto o movimiento, de mayor o menor complejidad. Son bastante comunes la representación de figuras que sirven el té, llevan a cabo una caligrafia o lanzan una flecha.

\section{Tecnología y actualidad}

Como ya hemos comentado anteriormente, uno de los objetivos de este artículo es poner de relieve los nexos existentes entre la tradición y la modernidad, entendida como las creaciones de muñecas actuales que tienen lugar en el archipiélago nipón. Cabe destacar que existen multitud de ejemplos y tipologías, entre los cuales hemos escogido uno concreto como es el caso de las smart doll, que analizaremos más adelante. Hay que decir que de un tiempo a esta parte, la cantidad de nombres propios ha crecido considerablemente (refiriéndonos tanto a marcas como a creadores independientes) e, igualmente, se han adquirido creaciones extranjeras, como pudo ser en su momento el caso de las Blythe, de origen americano y producidas actualmente por la firma Takara. Ya sea por su estética o la funciones que van ligadas a su tipología, en la mayoría de los casos nos vamos a encontrar una modernización de las llamadas ishōningōo muñecas de vestir, dando lugar a lo que a día de hoy se conoce como fashion doll. Estas piezas, como bien indica su nombre, son pequeños figurines destinados ya sea a un público adulto o infantil, donde lo más llamativo es la ropa, los complementos y el peinado. Como un claro ejemplo de esto podemos referirnos a la Barbie occidental o la Licca-chan japonesa: maniquíes muy básicos en su construcción a los que peinar y cambiar la ropa a gusto del consumidor. No obstante, sobra decir que existen otros tantos ejemplos en el mercado, diferenciándose unos de otros por la calidad de los materiales (tanto en la construcción del cuerpo, el cabello o el atuendo y accesorios) y la media de articulaciones, lo que viene a determinar su coste y, por ende, marcar el espectro de público al que se dirigen.

Groove, Volks, Azone o Takara son, entre otras muchas, algunas marcas creadoras y distribuidoras de distintas fashion dolls que se dirigen, sobre todo, a coleccionistas adultos. Cada una de estas piezas cuenta con unas características que la diferencian del resto, por ejemplo, en el caso de Groove (una marca en inicio coreana que actualmente distribuye la firma japonesa) o Takara sus muñecas tienen una ligera macrocefalia que incide o aporta un aspecto más cercano a la estética kawaii, a lo que se suma la escala de las piezas. Azone, por otro lado, sus figuras son mucho más pequeñas cuyo tratamiento se acerca al manganime en elementos como el diseño de los rostros (destacando los ojos) o incluso en el cabello voluminoso y con colores imposibles. Volks es una de las marcas pioneras en el lanzamiento de BJD o Ball Jointed Dolls, en estos casos distinguimos escalas mucho más grandes y un aspecto realista que, según el tratamiento de las piezas, puede acercarse al valle de lo inquietante. Son ejemplos muy distintos que se mueven en un mismo mercado y que obedecen a las características de las fashion doll, además de aportar toda una serie de aspectos customizables (modificación de la pintura facial, cambio de pelucas ya que el cabello no está cosido a la cabeza, intercambio de globos oculares, creación de híbridos con distintas cabezas y cuerpos) para experimentar y adaptar la muñeca al gusto del coleccionista. Como ya hemos mencionado, estos son sólo algunos ejemplos.

Considerando lo anteriormente expuesto, vemos una clara referencia a ciertas tipologías tradicionales poniendo de relieve, por supuesto, algunas modificaciones dadas por los cambios en los sistemas de producción y la consideración de estas muñecas. Por supuesto y como ya hemos anotado anteriormente, el vínculo que establecemos en este caso nos remite a las ishō-ningyō, por ese carácter expositivo, así como por la importancia del tratamiento de los tejidos y peinados. No obstante, tenemos que señalar importantes diferencias que aluden a la consideración de estas piezas como objeto de carácter artístico y único: la función fundamental de las ishō-ningyō es la contemplación y exposición, son piezas únicas fabricadas de forma artesanal y por tanto no modificables que permanecen inalteradas tal y como

\footnotetext{
2 Senda, Y. (2012).

13 Boyle, K. (2008).

14 Pate, A. S. (2005b): 224.
} 
el creador las diseñó, acercándose a través de estas premisas a un objeto artístico inmutable y que no es de recibo que se pueda cambiar, ya que su creador lo ha concebido así. Evidentemente, con la entrada de nuevos materiales y técnicas, la producción artesanal queda limitada a unos pocos casos que no hacen sino poner de relieve el valor de esos ejemplares limitados y artesanales. La mayoría de los que hemos seleccionado en el presente texto y que nos remiten a modelos actuales se sirven de estos medios de fabricación masivos que sí incorporan procesos manuales, pero quedan reducidos a su mínima manifestación y, por lo tanto, quedan englobados en una producción en masa cuyo fin es atender la demanda del mercado. El hecho de que en la actualidad se prime ese carácter customizable nace de la necesidad por parte de los coleccionistas de hacer sus muñecas únicas, de convertirse en artesanos que, a partir de un modelo genérico, pueda crear su propia muñeca al gusto, haciéndola única y completamente personal.

Centrándonos ya en las muñecas que nos ocupan, las smart doll, a la hora de abordar estas piezas vamos a empezar dando unas breves pinceladas acerca de la trayectoria profesional y biografía de su creador, Danny Choo. A pesar de sus orígenes británicos, ya desde muy joven mostró interés por la cultura popular japonesa, lo que le llevó a especializar su formación en el estudio y dominio del idioma. Gracias a ello, empezó a trabajar para Japan Airlines, y con posterioridad, para distintas compañías (como Amazon) cuya producción estaba estrechamente ligada a la creación de tecnología. Fue en el año 2007 cuando funda su propia compañía, una startup llamada Mirai Inc. dedicada a la creación de software para pequeñas y medianas empresas de todo el mundo. Además, y en consonancia con su interés por Japón, Choo dirige un programa televisivo llamado Culture Japan (2010) ${ }^{15}$ dedicado a la difusión de diferentes aspectos populares de la cultura del archipiélago japonés. Esta propuesta contaba con el propio creador como presentador, acompañado de la muñeca Mirai Suenaga, de la que hablaremos posteriormente, y se emitió, concretamente, en la televisión nipona y en otras zonas de Asia gracias a Animax Network.

Si bien, y atendiendo al tema del presente texto, lo que nos interesa especialmente es la creación de sus muñecas, las smart doll, donde entra en juego la mencionada Mirai Suenaga ${ }^{16}$, originalmente, mascota de la empresa de Choo. Este es un personaje femenino de apariencia juvenil y estética cercana al manganime y al kawaii cuya primera aparición la encontramos en una de las propuestas de Mirai Inc. nada más y nada menos que una aplicación móvil para el aprendizaje de la lengua japonesa a través de un juego de cartas con los diferentes ideogramas, donde aparecían personajes de diseño simplificado entre los que se encontraba la propia Mirai. Atendiendo a su estética, su popularidad empezó a crecer hasta tal punto que otras empresas dedicadas a la producción de juguetes y figuras, como puede ser el caso de Good Smile, se interesaron en lanzar productos que tuvieran la efigie de este personaje. Así, atendiendo a esta situación, Danny Choo tomó la decisión de lanzar al mercado su propio merchandising, destacando, con la fashion doll de Mirai Suenaga como producto estrella, bajo la marca Smart Doll, ya que, con posterioridad, van a ir apareciendo nuevos personajes pertenecientes tanto al juego de cartas como al universo de Mirai ${ }^{17}$.

Estas son unas muñecas de escala 1/3, es decir, de unos 60 centímetros de altura, con cuerpos proporcionados con unos 11 puntos de articulación, ojos insertados y pelucas intercambiables. Como ya hemos comentado, la construcción del rostro es similar a la de un personaje de manganime, con ojos bastante grandes y una nariz y boca estilizadas y simplificadas. Esta inspiración en el anime les ha brindado toda una serie de posibilidades a la hora de sacar figuras basadas en personajes de series conocidas como Code Geass. No obstante, cabe destacar que en la actualidad se están dando distintos moldes con un toque más realista, aunque siempre manteniendo esa estética que las caracteriza.

A la hora de hablar del proceso de creación de estas muñecas, debemos señalar que aparece totalmente detallado en la página web correspondiente ${ }^{18}$, de modo que, a grandes rasgos, podemos señalar una serie de procesos que combinan el trabajo artesanal y la incorporación de nuevas tecnologías. A título de ejemplo de estos procesos, debemos hablar del curado de la resina, un procedimiento artesanal que, a su vez, trae consigo pequeñas diferencias (marcas mínimas o sutiles variaciones de color) entre una y otra muñeca, lo que, según Danny Choo, hace que cada pieza sea única. Lo mismo podemos ver respecto al lijado de distintas piezas o incluso en la elaboración de sus conjuntos y complementos confeccionados de forma manual. Por otro lado, como ya hemos mencionado, las tecnologías no se dan de lado, ya que destaca el uso de impresoras 3D para construcción de moldes, prototipos, o de las propias cabezas de las muñecas. En resumidas cuentas, a este respecto, podemos ver como Choo presta una especial atención a estas pequeñas creaciones, buscando algo a medio camino entre la artesanía y la producción en masa, cosa que se ve reflejada en su precio y también en su propia filosofía que, en palabras de Choo, toma algunos aspectos del wabi-sabi ${ }^{19}$.

No podemos olvidar que estamos ante una estrategia de marketing donde la aplicación e interpretación de estos conceptos desempeña un papel de puesta en valor de estas muñecas a manos de su propio creador. Bien es verdad que, teniendo en consideración su producción y características no deja de ser una caracterización "correcta": cuando se nos habla de fukinsei o asimetría podemos aludir al curado de la resina que ya hemos visto o bien a otros procesos artesanales que traen consigo ciertas diferencias entre las distintas figuras. Shizen, que es otro concepto propio del

\footnotetext{
Para más información acerca de Culture Japan véase: Choo, D. (2010).

6 Choo, D. (2014).

Se podría decir, en este aspecto, que sigue un modelo similar a otras muñecas de gran popularidad. Es el caso de Barbie o de la propia Licca, ya mencionadas. En ambos ejemplos se cuenta con una serie de personajes complementarios pertenecientes a la familia o al grupo de amigos del personaje que representa la muñeca.

18 Choo, D. (2013).

19 Choo, D. (2015).
} 
wabi-sabi remite a la ausencia de artificio, este caso es relativo ya que bien es verdad que estamos viendo fotografías del producto y una gran cantidad de información a nuestra disposición en todo momento, abundante y verdadera, pero, como decimos, es un producto, y a pesar de mostrarlo de forma natural cada toma esta medida, cuidada y posiblemente retocada digitalmente. Por último, el tercer rasgo en el que se apoya Choo es datsuzoku o libre de convenciones, y es verdad que esta tipología de muñecas incluye una serie de innovaciones que las hacen diferentes del resto, aunque sí que están limitados a un tipo de articulación y a unos moldes que, aunque diferentes, beben de otras piezas. En resumidas cuentas, la definición general que conocemos del wabi-sabi y su relación con las smart doll es algo relativo que ha de tomarse con cautela ${ }^{20}$, aunque se aplica, o más bien se interpreta de forma inteligente y siempre como una estrategia más para ensalzar las cualidades del producto a la venta, lo que, a su vez, contradice en mayor o menor medida esta filosofía. No debemos olvidar que Mirai, o cualquiera de las muñecas pertenecientes a la firma Smart Doll, es un producto de cierto lujo, de precio elevado, lo que nos lleva a pensar inmediatamente en un consumidor adulto pero, como muestra el propio Choo en sus redes sociales, también conquista a los niños y niñas que, junto con sus familias, visitan su tienda en Tokio para hacerse con una preciosa muñeca, sea por su belleza, por las preciosas imágenes que van unidas al producto, por sus innovaciones o por la filosofía que Choo construye en torno a su creación, las ventas son elevadas, por lo que sus distintas estrategias funcionan.

Algo que nos llama la atención de estas figuras, y que va en consonancia con la creatividad e innovación, es su diseño. Las Smart Doll pertenecen a la tipología BJD, Ball Jointed Dolls, que, como bien indica su nombre, cuenta con una serie de articulaciones en forma de bola en las extremidades, lo que les permite doblar codos, muñecas, rodillas y tobillos. Normalmente, las BJD cuentan en su interior con una estructura sustentada por un par de gomas tensas que permiten que las piezas se mantengan unidas y la figura doble sus partes correctamente; si bien, en este caso, nos encontramos con un diseño mucho más práctico que no necesita cambios de gomas o este tipo de mantenimiento: las extremidades de las muñecas son piezas encajadas y en su interior cuenta con un esqueleto de bolas a modo de columna vertebral que le da más margen de movimiento y deja el interior del torso prácticamente hueco. Igualmente, otros de los aspectos que resultan interesantes a la par que útiles para los coleccionistas es el hecho de que en la parte baja de la espalda cuenten con un orificio en el que se introduce el stand o soporte para que se mantengan en pie. Esto permite la toma de fotografías de forma rápida y mucho más sencilla, sin que la muñeca sufra un percance o daño al caerse y dando la posibilidad de conseguir un aspecto mucho más realista en la imagen, además de poder transportarse fácilmente y no ocupar apenas espacio a la hora de exponer.

Respecto a su interior hueco, es uno de los factores que han sido aprovechados por Choo a la hora de dar un nuevo enfoque a su producto, ya que la muñeca deja de ser un objeto de colección y exhibición, o un mero juguete, para pasar a convertirse en un accesorio de utilidad más. El diseño del tronco de estas muñecas y su tamaño permite introducir en su interior distintos dispositivos tecnológicos, como puede ser un disco duro externo, la batería del ordenador, una batería portátil o, incluso, como nos muestra Choo, algunos snacks para llevar contigo. Si a esto le sumamos el orificio en la parte trasera destinado al stand, permite sacar ciertos cables sin problema y sin tener que, necesariamente, desmontar a la muñeca ${ }^{21}$. La implicación con las nuevas tecnologías ha llegado hasta tal punto que la propia firma Smart Doll ha lanzado su propia batería portátil con el tamaño adecuado para introducirse en el torso de la muñeca, sea el molde masculino o femenino, y un diseño que, de nuevo, permite mantenerla en su interior sin problema $^{22}$. Igualmente, el hecho de que estas muñecas puedan ser customizadas a la hora de comprarlas (es decir, que el consumidor puede modificar ciertos aspectos de la pieza, como puede ser el tamaño del pecho o el tono de la piel) juega en favor de lo que hemos comentado, ya que se pueden incluir orificios o incluso puertos USB a gusto del consumidor para que pueda tener una «experiencia Smart Doll» completa y pueda llevar a su muñeca a todas partes como un objeto que cubra ciertas necesidades.

\section{Conclusiones.}

En primer lugar nos gustaría señalar que, a pesar de que en este texto hemos mencionado fundamentalmente creadores y firmas niponas, existen multitud de nombres propios y casas en todo el mundo, incluyendo excelentes nombres en nuestro país. Esto no hace sino poner de relieve la difusión de estas piezas en todo el mundo, así como la libertad creadora que traen consigo, lo que queda patente si nos detenemos a mirar los diferentes moldes faciales y corporales, los sistemas de articulación, la creación de atuendos, de híbridos y un largo etcétera que no hacen otra cosa que enriquecer el mundo del coleccionismo y la creación artesanal de muñecas.

Hemos hablado de ciertas conexiones entre la tradición y la modernidad poniendo de relieve la herencia de algunas características e interpretaciones de tipologías tradicionales, haciendo alusión a las llamadas fashion doll para coleccionistas sin dejar de lado, por supuesto, su concepción más básica como juguete infantil, algo existente tanto en el pasado como en el presente, aunque las tipologías a las que hemos hecho alusión, fundamentalmente se dirigen a un público adulto. No obstante, también somos conscientes de las variaciones más que evidentes, entre las cuales queremos destacar los métodos de producción y la consideración y función de las muñecas. Como ya hemos

\footnotetext{
20 Para saber más acerca de la estética wabi-sabi y su aplicación en la contemporaneidad véase: Ramos González, A. (2014).

21 Choo, D. (2016b).

22 Choo, D. (2016a).
} 
visto, a día de hoy estas figuras son un objeto que se produce en masa mediante una serie de procesos mecanizados que se combinan con otros artesanales mínimos aplicados a aspectos muy concretos; esto rompe con las tipologías tradicionales, ya que cada modelo no es precisamente único y original, no obstante, cada pieza es hija de su tiempo ya que no podemos olvidar el contexto que la rodea y que, en este caso, alude a una importante evolución en el descubrimiento de nuevos materiales y técnicas productivas. Mucho más interesante es el cambio en la concepción de las muñecas, que tradicionalmente consistían en piezas únicas e inalterables condicionadas por las capacidades y la búsqueda estética de sus creadores, en el presente este rol en muchos casos recae sobre el propio coleccionista y consumidor, ya que se le da la posibilidad y las herramientas de, si lo prefiere, cambiarlas y adaptarlas a su gusto y necesidades, construyendo, como resultado, una pieza única (OOAK, One Of A Kind), para su venta o bien para el disfrute personal.

Por supuesto, existen otros creadores como los que mencionamos al principio de este apartado más afines al concepto tradicional y artesanal, diseñando sus piezas y comercializándolas de forma autónoma. En resumidas cuentas, detrás de cada muñeca hay un diseñador o diseñadora, sea parte de una empresa o sea un creador independiente, y sobre este interviene una producción ya sea en masa o bien más selectiva, donde se aplican nuevos medios.

En consonancia con esto, vemos un más que evidente aprovechamiento de las nuevas tecnologías, tanto a la hora de producir como a la hora de difundir las distintas muñecas. Ya hemos comentado que Choo utiliza elementos como impresoras 3D a la hora de elaborar piezas y prototipos, este es un solo ejemplo entre otros tantos. Por otro lado, la implementación de elementos tecnológicos es algo que otorga a estas piezas un sentido práctico e invita a los coleccionistas a sacarlas de las vitrinas para transportarlas y realmente disfrutarlas. En estos casos, el componente tecnológico es un accesorio aparte, pero en el caso de las smart doll se han difundido imágenes y videos donde las muñecas cuentan con partes robotizadas que les permiten moverse y ejecutar algunos gestos. Evidentemente, todo son meras pruebas, pero hablan de futuras intenciones y quizás tempranas creaciones afines a las karakuri-ningyō que hemos definido, si bien, los mecanismos de madera dan paso a elaboraciones mucho más complejas.

En última instancia, nos gustaría detenernos en un aspecto más interesante e incluso relevante, como es el caso de la diversidad. Hemos comentado brevemente los distintos creadores y las amplias posibilidades a la hora de crear y diseñar que traen consigo estas muñecas. Esto puede reflejarse, por ejemplo, en el caso del tratamiento de los cuerpos: fundamentalmente a lo largo de los años nos hemos encontrado con formas estilizadas que aúnan en esa idea de la muñeca como maniquí, de tal modo que sus formas quedan reducidas en favor de la ropa y tejidos, ya que no podemos olvidar que los tejidos obedecen a una escala mayor y, por ello, las piezas textiles se ven mucho más voluminosas sobre la muñeca, por eso, con el fin de dotarla de mayor realismo, el cuerpo de estiliza y en ocasiones incluso se reduce. No obstante, de un tiempo a esta parte y gracias a la creatividad e innovación, cada vez son más los creadores que huyen de estas concepciones, dando lugar a muñecas con cuerpos frágiles e imposibles como podemos ver en el caso de Doll Chateau, mientras que otras toman formas más robustas y realistas como Iplehouse. En relación con esto último y ahondando en el tema del realismo, aspectos como prótesis ortopédicas, marcas, cicatrices, o enfermedades como el vitíligo están siendo cada vez más visibles y evidentes, lo vemos en el caso de las smart doll, pero también en ejemplos más cercanos a nosotros como el caso de Mattel que en una de sus últimas líneas de Barbie Fashionista ha incorporado muñecas en silla de ruedas o una de ellas con una pierna protésica. Gracias a la creatividad y a la difusión de creaciones como estas las muñecas ya no sólo son meros elementos de juego o exposición, sino que son piezas que favorecen la normalización de ciertos aspectos sin coartar la libertad artística de diseñadores, ya sean grandes empresas o nombres independientes.

La variedad de formas y tipologías, o el hecho de que tiendan cada vez a un mayor realismo y cercanía con la sociedad del presente, es algo que también nos remite a la tradición, ya que no podemos olvidar la gran variedad de muñecas tradicionales japonesas existentes (que no nos hemos parado a definir en este caso), pero cuyas formas y funciones son ricas y prácticamente inabarcables siendo, fundamentalmente, un reflejo de la sociedad de su momento. Bien es verdad que el hecho de que tuvieran unos objetivos rituales o como talismán justificaban esta diversidad, pero también los distintos sectores de la sociedad y sus demandas eran un factor importante a tener en cuenta, lo mismo que ocurre en estos casos, donde la variedad viene determinada por los movimientos del mercado y las exigencias de los consumidores. Bien es verdad que existen creadores contemporáneos de ningyō propiamente dichas con nexos más evidentes con la definición que hemos establecido al principio y con piezas más cercanas a la consideración de lo que es arte, pero otros objetos afines a los medios de masas y de consumo también los tienen, de manera menos evidente, como ya hemos visto. Durante el periodo Edo (1603/1615-1868) las muñecas se convirtieron en un objeto de consumo que se extendió entre las distintas clases de la sociedad, experimentó un crecimiento más que evidente y su producción llegó a alcanzar lo que se considera como excelencia ${ }^{23}$, estos son elementos que nos acercan a un presente donde cada vez son más las personas que descubren el mundo de las muñecas, el aumento de creadores y moldes es algo más que evidente y quizá no se haya alcanzado la excelencia, pero al menos la originalidad y variedad están presentes. 


\section{Bibliografía}

Boyle, Kirsty (2008): Karakuri. Info. Kirsty Boyle. http://www.karakuri.info/origins/index.html [Consulta: 18/03/2020]. Choo, Danny (2010): Culture Japan. Danny Choo. https://archive.dannychoo.com/en/posts/culture-japan-1 [Consulta: $18 / 03 / 2020]$.

Choo, Danny (2013): The Making of a Smart Doll. Danny Choo. https://archive.dannychoo.com/en/posts/the-making-ofsmart-doll?lang=en [Consulta: 18/03/2020].

Choo, Danny (2014): Mirai Suenaga. Danny Choo. https://archive.dannychoo.com/en/posts/mirai-suenaga?lang=en [Consulta: 18/03/2020].

Choo, Danny (2015): Design Philosophy. Danny Choo. https://archive.dannychoo.com/en/posts/designphilosophy?lang=en [Consulta: 18/03/2020].

Choo, Danny (2016a): Miraicon. Danny Choo. https://archive.dannychoo.com/en/posts/miraicon?lang=en [Consulta: $18 / 03 / 2020]$.

Choo, Danny (2016b): Smart Charge Mirai. Danny Choo. https://dannychoo.com/en/posts/smart-charge-mirai [Consulta: 18/03/2020].

Gómez Pradas, Muriel (2011): El movimiento Mingei en las colecciones del Museu Etnològic de Barcelona. El caso de los kyō do-gangu o juguetes populares y tradicionales japoneses. Tesis doctoral dirigida por Elena Barlés Báguena, Departamento de Historia del Arte, Universidad de Zaragoza.

Gribbin, Jill / Gribbin, David (1984): Japanese Antique Dolls. New York: Weatherhill.

Medina, Guillem / Simón, Núria (2013): Toyland. Made in Asia. Bilbao: Astiberri Ediciones.

Pate, Alan Scott (2005a): Antique Japanese Dolls [página WEB], Alan Scott Pate. http://www.antiquejapanesedolls.com/ pub_artinfocus/sosaku_ningyo/sosaku_ningyo.html [Consulta: 18/03/2020].

Pate, Alan Scott (2005b): Ningyō. The art of the Japanese doll. Singapur: Tuttle Publishing.

Ramos González, Alicia (2014): "Historia del vacío todopoderoso. Reflexiones sobre arte Zen y la estética contemporánea". En: Cartaphilus: Revista de Investigación y Crítica Estética, 12 [vol.], Murcia, pp. 244-252.

Senda, Yasuo (2012): Karakuri ningyo. Japanese automata. Nagoya: Senda Yasuko Publishing.

Whitney, John (ed.) (1991): The Cambridge History of Japan. Nueva York: Cambridge University Press.

Yamada, Tokubei (1955): Japanese Dolls. Tokio: Japan Travel Bureau. 